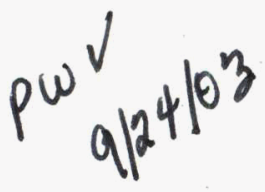

SAPPHIRE FIBER OPTICS SENSORS FOR ENGINE TEST INSTRUMENTATION

Mark A. Janney and Stephen D. Nunn

Oak Ridge National Laboratory

and

Russell G. May

Prime Photonics, Inc.

Date Published August 2003

Prepared for

Prime Photonics, Inc.

Blacksburg, VA

Prepared by the OAK RIDGE NATIONAL LABORATORY

Oak Ridge, Tennessee 37831

managed by

UT-BATTELLE, LLC.

for the

U. S. DEPARTMENT OF ENERGY

under contract DE-AC05-00OR22725

APPROVED FOR PUBLIC RELEASE

UNLIMITED DISTRIBUTION 


\begin{abstract}
This document is the final report for the Cooperative Research and Development Agreement (CRADA) between UT-Battelle and Prime Photonics, Inc. The purpose of this CRADA was to improve the properties of single crystal sapphire optical fibers for sensor applications. A reactive coating process was developed to form a magnesium aluminate spinel cladding on sapphire optical fibers. The resulting clad fiber had a numerical aperture, NA, of 0.09 as compared with 0.83 for the unclad fiber, dramatically enhancing its usefulness for sensor applications. Because the process allows one to control the diameter of the sapphire core within the fiber, it may be possible using this technology to develop waveguides that approach single-mode transmission character.
\end{abstract}

\title{
PROGRAM OBJECTIVES
}

The objective of this CRADA was to develop an optical fiber cladding and a process for applying the cladding to single crystal sapphire fibers that will enable Prime Photonics, Inc. to improve sensors based on sapphire fiber interferometry.

\section{Benefits to the Funding DOE Office's Mission}

This was a 100\% Funds-in CRADA and, therefore, no DOE funds were spent. 


\section{TECHNICAL DISCUSSION}

$\underline{\text { Introduction }}$

Prime Photonics, Inc. proposes to develop novel, self-calibrating temperature and pressure sensors for high temperature and harsh environment operations that are constructed using single crystal sapphire optical fibers. The sensors would fulfill the need for real-time, accurate monitoring of temperatures and pressures in environments such as those found in aircraft gas turbine engines. Rugged, self-calibrating temperature and pressure sensors are technological devices that would enable improved process control optimization in many industries.

Commercially available sapphire fibers are thin cylindrical single crystal filaments without optical claddings. The waveguiding structure is formed by the sapphire core and the surrounding air, which functions as an equivalent cladding. Due to the large refractive index difference between the sapphire fiber and the air, these fibers have a very large numerical aperture (NA), are highly multi-moded, and show high sensitivity to bends in the fiber. In addition, the intensity of the optical signal propagating in the fiber can be easily affected by changes in the surrounding atmosphere, such as refractive index variations and physical contacts, which are unavoidable in many applications. These problems make the fabrication of sapphire fiber sensors extremely difficult. For example, the highly multi-moded nature of the sapphire fibers requires a precision of angular alignment of the sapphire fiber to an order of 0.1 degrees in sapphire fiber interferometers, while communication-grade silica fiber-based interferometry requires a precision of only several degrees. Development of the materials and processes to produce suitable claddings on single crystal sapphire optical fiber waveguides would reduce or eliminate all of the problems mentioned above. If the full capabilities of single crystal sapphire sensors are to be realized, development of suitable cladding materials is imperative.

An effective cladding must have an effective index of refraction, $n$, that is slightly lower than that of the fiber ( $n=1.76$ for sapphire) and must be chemically and mechanically compatible with the fiber. Magnesium aluminate spinel, $\mathrm{MgAl}_{2} \mathrm{O}_{4}$, is a chemical compound that satisfies these requirements. It has an index of refraction of 1.72 and is compatible with sapphire, which is essentially pure alumina, $\mathrm{Al}_{2} \mathrm{O}_{3}$.

\section{Cladding Process Development}

A technique was developed for cladding sapphire with magnesium aluminate spinel. The technique involves dip coating a sapphire fiber in a suspension of $\mathrm{MgO}$ and spinel powders, drying the coating, then firing at elevated temperature to react the $\mathrm{MgO}$ powder with the sapphire fiber and to densify the coating. 
The overall reaction for the process is given by the chemical equation:

$$
\mathrm{MgO}+\mathrm{Al}_{2} \mathrm{O}_{3}=\mathrm{MgAl}_{2} \mathrm{O}_{4}
$$

which proceeds rapidly at $1750^{\circ} \mathrm{C}$.

Suspensions were made using four different blends of $\mathrm{MgO}$ (Analar Grade, EM Science, Savannah, GA) and $\mathrm{MgAl}_{2} \mathrm{O}_{4}$ (Baikowski International, Raleigh, NC) in the weight ratios of $100 / 0\left(\mathrm{MgO}_{\mathrm{MgAl}} \mathrm{O}_{4}\right), 75 / 25,50 / 50$, and $25 / 75$. The different ratios of $\mathrm{MgO}$ and spinel were selected to investigate what the effect might be of the amount of reaction between the coating and the sapphire substrate on the type of cladding formed, its thickness, and its microstructure. The more spinel in the initial coating, the lower the degree of reaction. Also, the spinel particles might provide seeds for crystal growth of the spinel formed by their action of $\mathrm{MgO}$ with sapphire, which would in turn affect the microstructure of the spinel cladding.

The powders were mixed by ball milling in a solution of isopropyl alcohol (90.2 wt. \%), propylene glycol methyl ether (8.2 wt. \%), polyvinylpyrrolidone (1.2 wt. \%, 10,000 MW, Aldrich Chemical Co., Milwaukee), and polyethylene glycol 200 (0.4 wt. \%, Dow Chemical Co., Midland, MI) to form a suspension having flow properties appropriate for a coating operation. Isopropanol is the primary solvent for the suspension, propylene glycol methyl ether is a drying control solvent which dries much slower than the isopropanol, polyvinylpyrrolidone is a dispersant which helps deagglomerate the powders and also acts as a temporary binder in the green state, and polyethylene glycol is a plasticizer for the polyvinylpyrrolidone. The suspension was formulated at 20 vol. $\%$ solids.

Fibers were dip coated in the suspensions and dried in air. In the most useful cases, multiple dip coatings were used. Reaction firing was done at $1750^{\circ} \mathrm{C}$ for 30 minutes in ultrahigh purity argon in a tungsten element furnace (R. D. Brew Co., Concord, NH).

Figure 1 shows results for three of the initial tests of this coating method. All of the samples formed a dense, adherent cladding of spinel on the sapphire. The thickness of the cladding formed was similar for the three cases shown here. The $75 / 25$ mixture was selected for further testing because it was judged to have the best overall appearance.

Having established that the technique was viable, the effect of slurry coating thickness on cladding formation was investigated. Samples were fabricated using 1, 2, 4, and 8 dip coatings. The results of those tests are shown in Figure 2. All of the samples exhibit a characteristic core-cladding geometry. The single-crystal sapphire core is easily differentiated from the spinel cladding by its distinctive cleavage steps.

The progress of this reaction is clearly of the "disappearing core" type. This is not surprising since the only source of alumina for the $\mathrm{MgO}$ to react with is the sapphire fiber itself. The initial sapphire fiber was about $400 \mu \mathrm{m}$ in diameter. For sample PP21013 with 4 dip coatings, the remaining sapphire core was reduced to about $200 \mu \mathrm{m}$ diameter. 
The thickness of the cladding varied linearly with the number of coating layers applied, at least up to four (Figure 3). This was somewhat surprising, since the amount of material added with each succeeding dip coat was greater than that contained in the previous coat, and the amount of sapphire that has to be converted decreases with each succeeding coat. This apparent linear relationship may be more fortuitous than anything else. However, it does provide a predictable method for controlling the sapphire core diameter.

Because the application for the clad sapphire fiber is as part of a fiber optic sensor, it was important to determine whether the spinel cladding actually affected the optical properties of the sapphire fiber. Figure 4 shows the normalized transmission intensity through the fiber as a function of the angle of incidence of the incoming laser light. Clearly, the clad fiber transmits over a much smaller range of input angle than does the uncoated fiber. Based on these measurements, one can calculate a numerical aperture, NA, for the unclad and clad fibers. The unclad fiber had a NA of 0.83; the clad fiber, 0.09 .

In theoretical design concepts, one would prefer to have a single-mode fiber for many sensor applications. The spinel-clad sapphire approach provides a method for potentially reaching that goal. The number of modes that an optical fiber (having a step index between core and cladding) can support is dictated by the NA of the fiber and the diameter of the core, according to the equation:

$$
\mathrm{N}=\mathrm{V}^{2} / 2=(2 \pi \mathrm{a} / \lambda) \mathrm{NA}
$$

where

$$
\begin{aligned}
\mathrm{N} & =\text { number of modes } \\
\mathrm{V} & =\text { normalized frequency }(\mathrm{V} \text {-number) } \\
\mathrm{a} & =\text { core diameter } \\
\lambda & =\text { wavelength, and } \\
\mathrm{NA} & =\text { numerical aperture. }
\end{aligned}
$$

For a given core/cladding system (such as sapphire/spinel), the core diameter controls the number of modes that can propagate through the fiber. Since the cladding process developed through this research allows control of the fiber core diameter, the number of modes that propagate down the fiber can also be controlled.

\section{Summary}

A reactive coating process was developed to form a magnesium aluminate spinel cladding on sapphire optical fibers. The resulting clad fiber had a numerical aperture, NA, of 0.09 as compared with 0.83 for the unclad fiber. Because the process allows one to control the diameter of the sapphire core, it may be possible using this technology to develop waveguides that approach single-mode transmission character. 

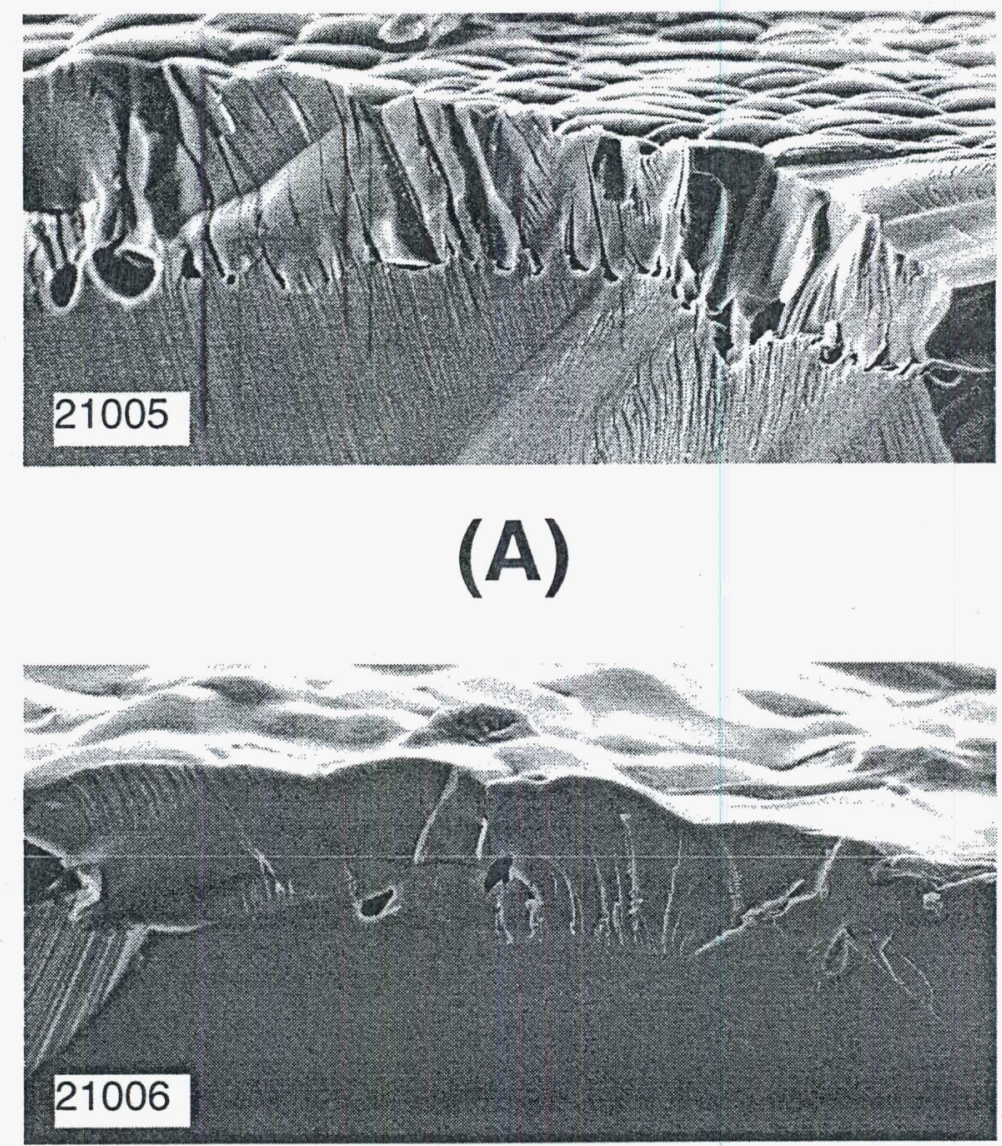

\section{(B)}

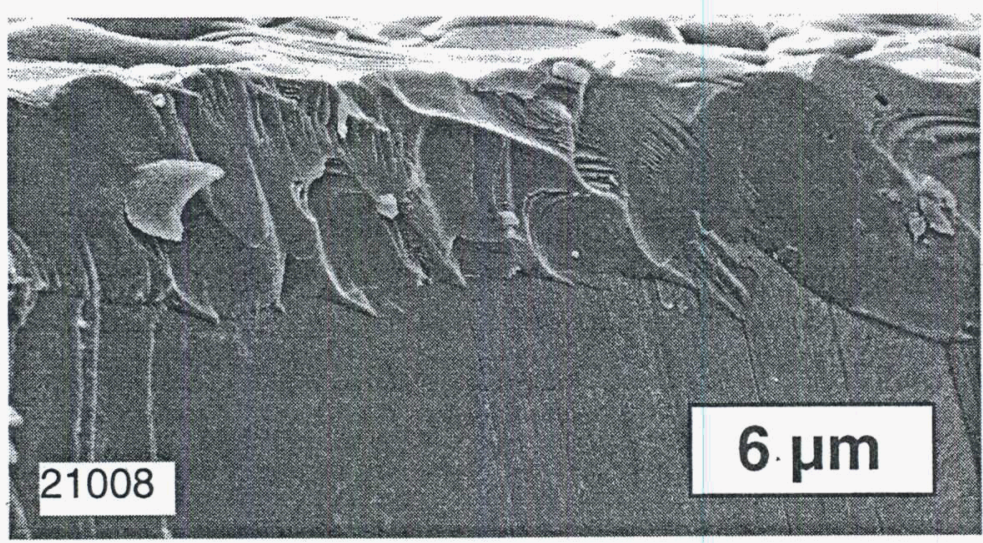

\section{(C)}

Figure 1. A dense coating of $\mathrm{MgAl}_{2} \mathrm{O}_{4}$ was formed on the surfaces of sapphire fibers after applying a single dip coating with (A) a $100 / 0 \mathrm{MgO} / \mathrm{MgAl}_{2} \mathrm{O}_{4}$ mixture, (B) a $50 / 50$ mixture, and $(\mathrm{C})$ a $75 / 25$ mixture of $\mathrm{MgO} /$ magnesium aluminate spinel then firing at $1750^{\circ} \mathrm{C}$ in argon. Fracture surface; SEM; original magnification $5 \mathrm{kX}$. 


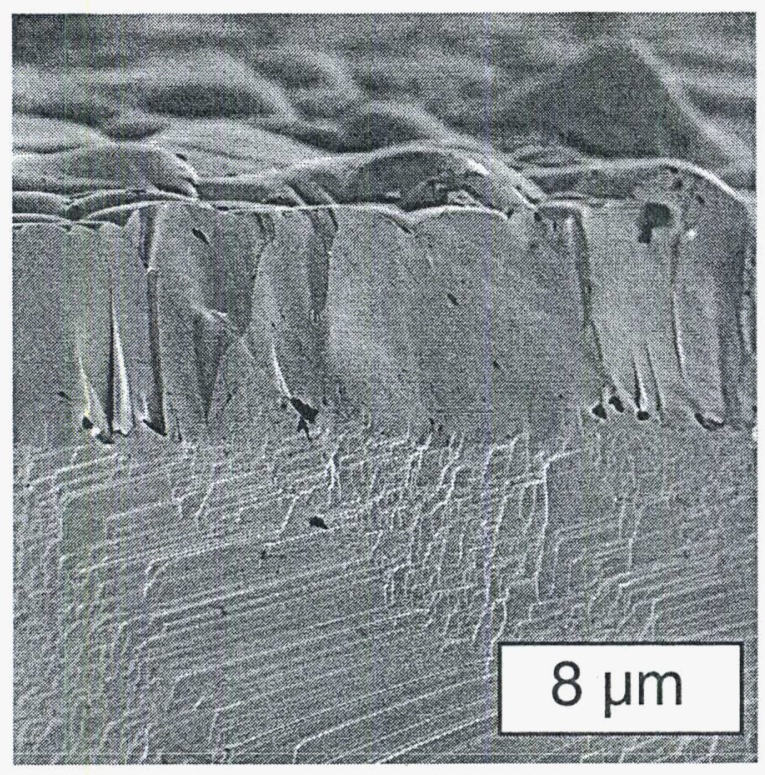

PP21009 75/25 MgO/Spinel, 1 dip coat

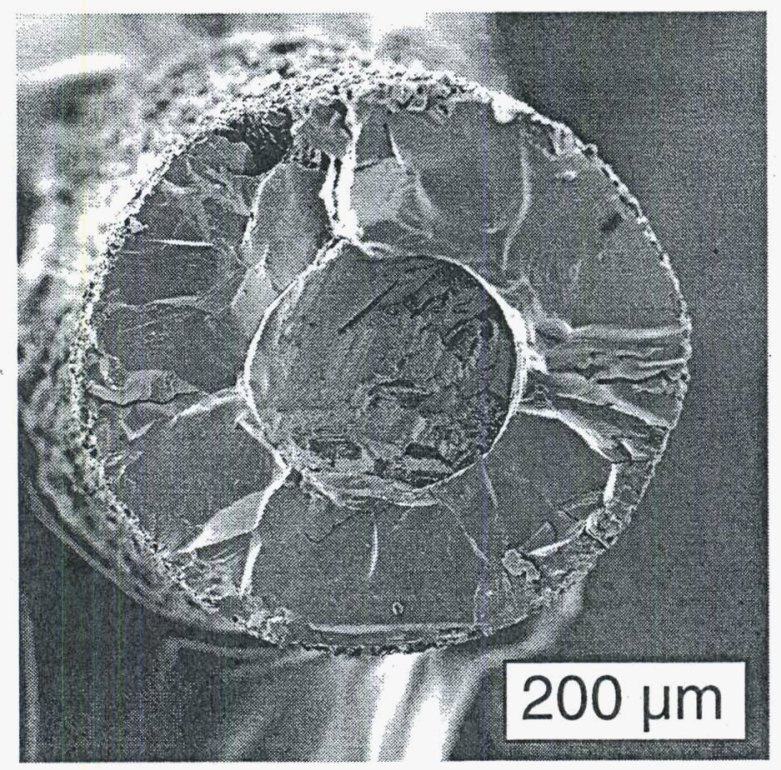

PP21013 75/25 MgO/spinel, 4 dip coats

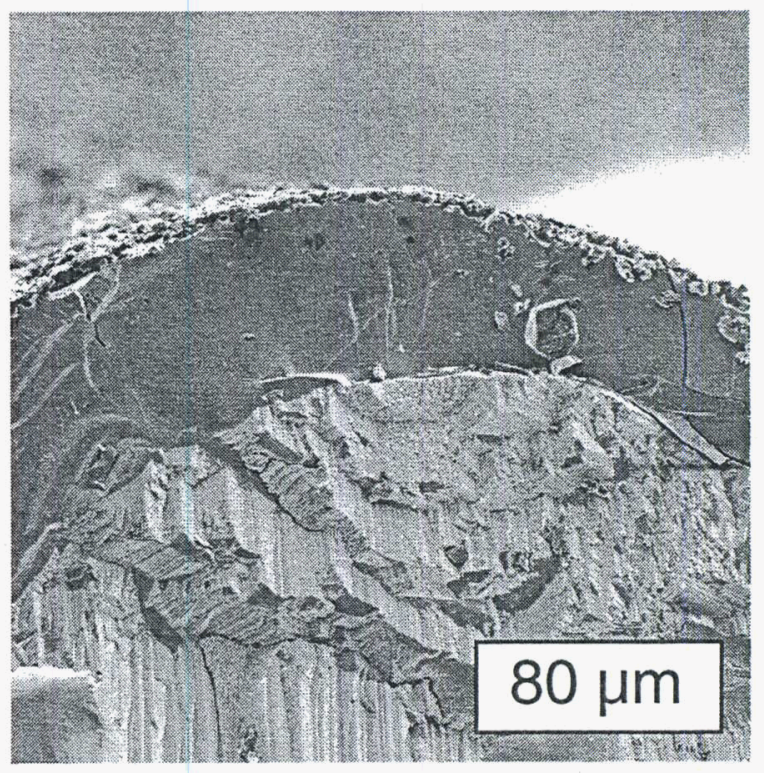

PP21010 75/25 MgO/Spinel 2 dip coats

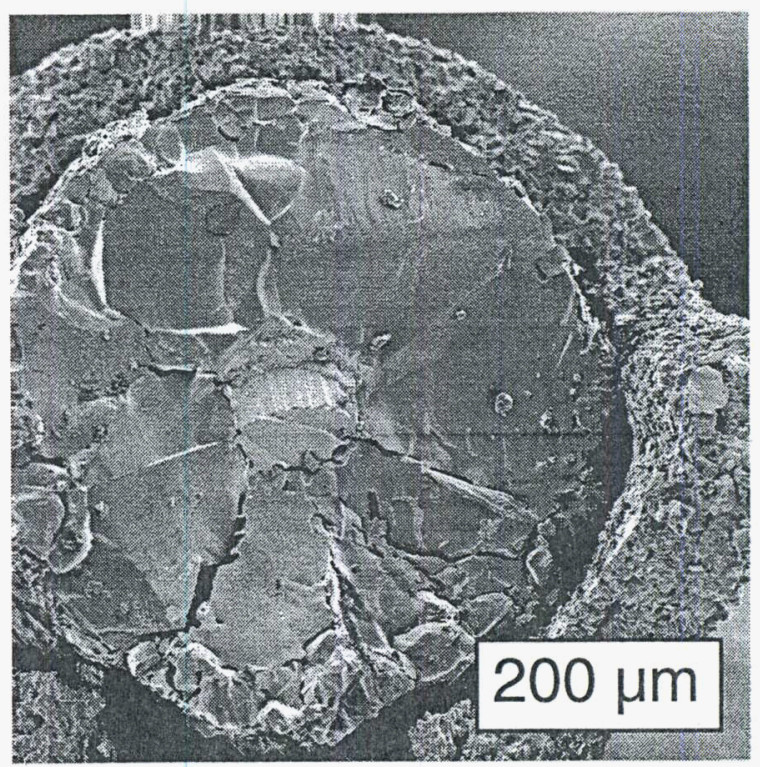

PP21012 75/25 MgO/Spinel, 8 dip coats

Figure 2. The thickness of the spinel coating developed on a sapphire fiber was dictated by the number of slurry coats put on in the green state. One dip coat produced a spinel coating about 5-6 $\mu \mathrm{m}$ thick. Eight coats converted the entire fiber to spinel. 


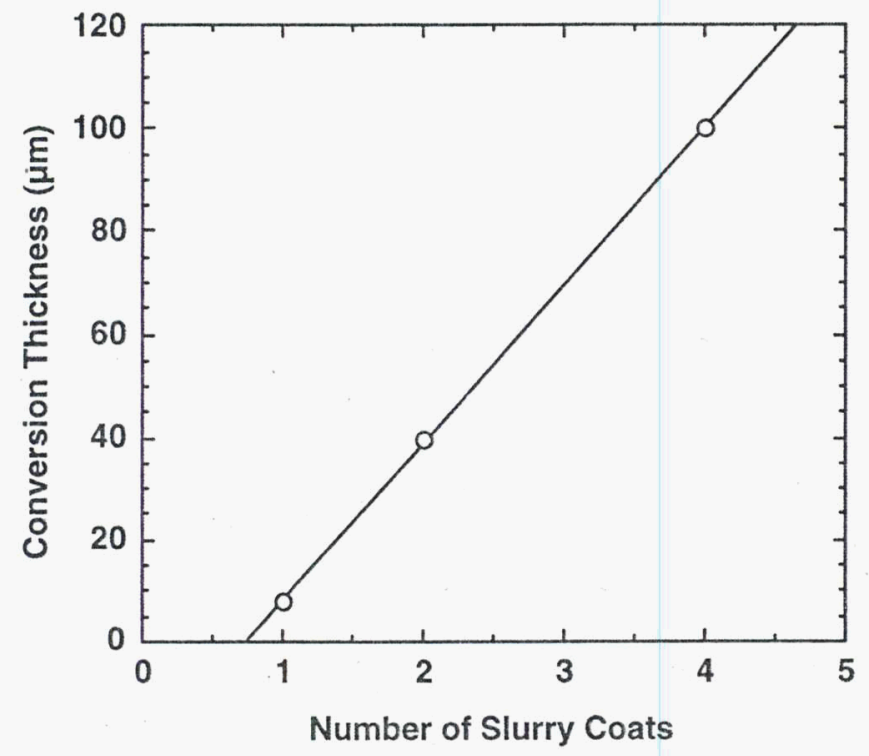

Figure 3. The sapphire conversion thickness increased linearly with the number of slurry dip coats on the sapphire fiber.

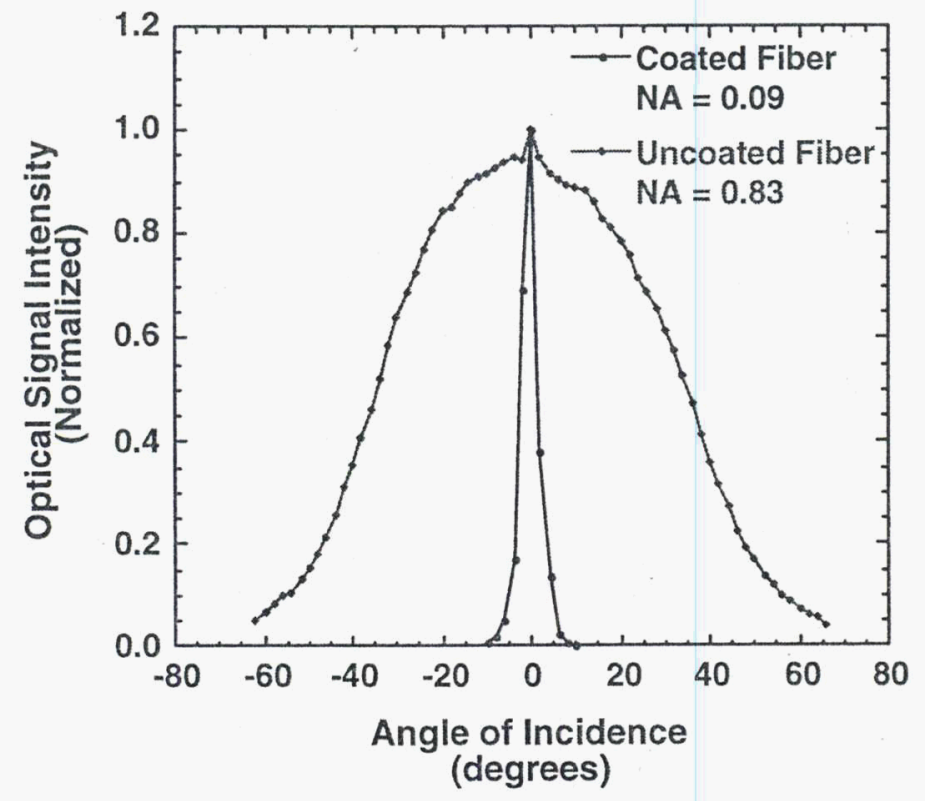

Figure 4. Normalized transmission output of $425 \mu \mathrm{m}$ diameter sapphire fiber before and after coating with $\mathrm{MgO} / \mathrm{MgAl}_{2} \mathrm{O}_{4}$. Two measurements were obtained for each case. The core diameter for this fiber was about $200 \mu \mathrm{m}$. 


\section{SUBJECT INVENTIONS}

Patent application entitled: "Cladding for High Temperature Optical Component and Method of Making Same"

\section{COMMERCIALIZATION POSSIBILITIES}

The results of this CRADA have increased the possibility for commercialization of sensors based on single crystal sapphire optical fibers.

\section{PLANS FOR FUTURE COLLABORATION}

There are currently no plans for future collaborations.

\section{CONCLUSIONS}

The objective of this CRADA was to develop an optical fiber cladding for single crystal sapphire fibers, which would enable Prime Photonics, Inc. to improve sensors based on sapphire fiber interferometry. A reactive coating process was developed to form a magnesium aluminate spinel cladding on sapphire optical fibers. The resulting clad fiber had a numerical aperture, NA, of 0.09 as compared with 0.83 for the unclad fiber, dramatically enhancing its usefulness for sensor applications. Because the process allows control of the diameter of the sapphire core in the clad fiber, using this technology it may be possible to develop waveguides that approach single-mode transmission character. 


\section{Distribution}

E. E. Bloom, $4500 \mathrm{~N}$, MS 6132

P. A. Carpenter, $4500 \mathrm{~N}$, MS 6269

P. J. Hadley, 4500S, MS 6161

D. R. Hamrin, 6011, MS 6254

R. G. May, Prime Photonics, Inc., 1872 Pratt Dr., Suite 1525, Blacksburg, VA 24060

S. D. Nunn, 4508, MS 6087

V. K. Sikka, 4508, MS 6083

T. M. Rosseel, 4500S, MS 6161

K. M. Wilson, 111 UNV, MS 6499

DOE-WFO, MS G209 
Final Report Certification
for
CRADA Number ORNL-00-05BG

$\because$ Between

UT-Ballelle, LLC

and

Prime Pholonles, inc.

(Participant)

\section{Instuctions:}

Mark the appropriate statement in "a or tb below with an "X." Reter to the articles in the CRADA tems and condfitions governing the identitictlon and marking of Proiected CFADA Information.

If no PCl is idenlifed, the report will be distributed whthout restrlation. If PCI is identifed. the report distribution will be limited in acoandance with the CRADA tarms and conditions gaveming release of date. In all cases items 2 and 3 must be irue. That is, the reporl cannot conlain Proprietary Information and a disctosure must be filed prior to retaase of the report.

This certicication may either be made by using this form or may be made on company letterthead if the Particlpant desires. A faxed copv of this completed form is accoptable.

The following certfleation is made for the subject Inal report:

1. (a) The final report contains information that qualifies as "Protected CRADA Information" (PCI). The PCl legend is printed on the report cover, and

OR the $\mathrm{PCl}$ is clearly identified.

$\mathcal{X}$ (b) The tinal report does not contain "Protected CRADA Information." The "Approved for Public Release" legend is printed on the report cover.

2.T he final repont does not contain Proprietary Information.

3.By the signature below, the Participant has no objection to the public distribution of the final report due to patentable infomation.

For the Participant

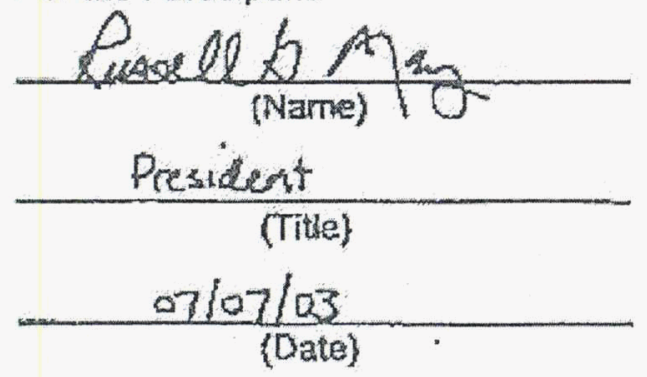

